\title{
Correction to: Assessing COVID-19's "known unknowns": potential impacts on marine plastic pollution and fishing in the South China Sea
}

\author{
Michael Heazle ${ }^{1,2}$
}

Published online: 21 January 2022

c) Springer-Verlag GmbH Germany, part of Springer Nature 2022

Correction to: Maritime Studies (2021) 20:459-474

https://doi.org/10.1007/s40152-021-00237-y

The publication of this article unfortunately contained a mistake in the first sentence of the introduction. Correct this sentence should be:

At the initial height of the COVID-19 pandemic's spread within and between countries in April 2020, over 4 billion people had been confined to their homes or had their movement severely restricted (Bates et al. 2020: 2).

The original article has been corrected.

Publisher's note Springer Nature remains neutral with regard to jurisdictional claims in published maps and institutional affiliations.

The original article can be found online at https://doi.org/10.1007/ s40152-021-00237-y.

Michael Heazle

m.heazle@griffith.edu.au

1 Kyoto University of Foreign Studies, Kyoto, Japan

2 Griffith Asia Institute, Nathan, Australia 